\title{
Tomato-Harvesting-Robot Competition Towards Smart Agriculture
}

\author{
Kazuo Ishii ${ }^{1}$, Takayuki Matsuo ${ }^{1,2}$, Yasunori Takemura ${ }^{1,3}$, Takashi Sonoda ${ }^{1,3}$, \\ Yuya Nishida $^{1}$, Shinsuke Yasukawa ${ }^{1}$, Takuya Fujinaga ${ }^{1}$ \\ ${ }^{1}$ Center for Socio-Robotic Synthesis, Kyushu Institute of Technology, 2-4, Hibkinino, Wakamatsu \\ Kitakyushu, Fukuoka 808-0196, Japan \\ ${ }^{2}$ National Institute Technology, Kitakyushu College \\ 2-20-1, Shii, Kokuraminami-ku, kitakyushu-shi, Fukuoka, Japan \\ ${ }^{3}$ Department of Engineering, Nishinippon Institute of Technology, 1-11 Aratsu, Kanda, \\ Miyakogun, Fukuoka 800-0394, Japan
}

E-mail: ishii@brain.kyutechg.ac.jp,matsuo@kct.ac.jp,takemura@nishitech.ac.jp,sonoda@nishitech.ac.jp, y-nishida@brain.kyutech.ac.jp,s-yasukawa@brain.kyutech.ac.jp, fujinaga.takuya835@mail.kyutech.jp1

\begin{abstract}
In agriculture, the aging and depopulation of farmers cause the shortages of farmers and manpower. Most of commercialized robots are industrial robots for factory automation, and most of robots for the first industry, agriculture, forestry and fisheries are still under developing. The reasons are cost-efficiency of the robotization, safety of the works using robots, difficulty of outdoor operations, and knowledge transfer problem from farmers to computer, etc. As one of solutions for the problems, robot technology into the agriculture is expected to contribute to the laborsaving, improvement of production, production line automation, and also the management toward smart-agriculture. We organize the Tomato-harvesting-robot competition to offer the research field and welcome researchers into agricultural robotics.
\end{abstract}

Keywords: tomato harvesting, agriculture robot, smart agriculture, competition.

\section{Introduction}

In agriculture, a decrease in the number of farmers, an aging population, and a shortage of successors are significant problems. Ministry of Agriculture, Forestry and Fisheries of Japan reported that Japanese self-sufficiency ratio for food is about 40 percent, which is lowest level among developed countries. For such urgent problems, smart agriculture is expected to be an innovative method of utilizing robot technology and information communication technology, and researches aiming to realize smart agriculture have been carried out such as the autonomous operation of agricultural machinery, automation of harvesting, and monitoring of the field environment and crops, etc. Most of commercialized robots are for factory automation of automobile, and most robots for agriculture, forestry and fisheries are under developing. The reasons for the late social implementation are cost-efficiency of the robotization, safety of the works using robots, difficulty of outdoor operations, and knowledge transfer problem from farmers to computer, etc. If we can overcome these difficulties and implement the robots into agricultural fields, robots can contribute to the laborsaving, improvement of production, production line automation. Also, the management of agricultural products such as quality, quantity, and condition of environment become possible and the smart-agriculture will be realized.

For the autonomous operation of agricultural machinery, Noguchi proposed a robot farming system [1] that consists of intelligent robot vehicles to automate farming activities from planting to supplying products to consumers and described the importance of simultaneous operations by developing a multiple robot system. For the automation of harvesting, Kawamura et. al. developed a mobile robot with manipulator and proposed the tomato harvesting method using image 
processing and visual feedback [2][3]. Kondo et. al. proposed the method to improve the success ratio of tomato harvesting and speed-up technique [4][5]. Ota et. al. proposed the path planning method to pick up tomato [6]. Yaguchi et al. developed an end-effector that grasped a fruit using grippers and plucked it from the separation layer in the peduncle [7]. They described the results of harvesting experiments conducted on an actual farm, demonstrating that the harvesting time was shortened by improving the harvesting motion [8]. Yoshida et al. developed a robot that har- vested a cluster of cherry tomatoes [9][10]. They focused on detecting the peduncles that the robot required when harvesting the clusters. For the monitoring of the field environment and crops, Fukatsu et al. described a remote monitoring method that responded flexibly and dynamically to changes in the field environment for longterm field monitoring [11] which consists of field servers, small monitoring sensor nodes. Fukui et al. developed a robot that estimated the volume of tomato fruits to create a database of fruit growth [12] by detecting fruits based on a human attention model, saliency [13].

Tomato is one of important fruit vegetables and most tomatoes are produced in the greenhouses, or large-scale farms, where the high temperature and humidity, and long harvest age force the farmers heavy works. With an aim to promote the automation of tomato harvesting, we have organized the tomato harvesting robot competition. In this paper, we introduce the Tomato-Harvesting-Robot Competition.

\section{Tomato-Harvesting-Robot Competition}

The Tomato-Harvesting-Robot competition started in 2014 and 7 th competition was held in 2020, which consists of two leagues, the Senior League and the Junior League. The target competitors for Senior League are supposed to be the teams with automated robots, and the Junior League are for high school or junior high school students, whom are asked to build robots with LEGO Mindstorms.

\subsection{Senior League}

The Senior League supposes that teams composed of undergraduate, graduate students or developers join the league with tomato harvesting robots, and compete the accuracy and speed of harvesting. The two kinds of competition field are designed, the one is the rail-style area and another is the freestyle area. The rail-style area is designed to have the similar environment with the large-scale tomato factory, where pairs of pipes are arranged on the ground to control the temperature of the greenhouse, and pipes are also used as the rails for the platform trucks on which the workers sit down, harvest and carry tomatoes. The diameter of pipes is $50 \mathrm{~mm}$ and the distance between pipes is $600 \mathrm{~mm}$. The position of tomato is always adjusted between 800 to $1200 \mathrm{~mm}$ heights as the tomato plants are growing up. The free-style area is for the robots of general tomato fields in outdoor environment in future. In the first to 6th competitions, artificial grasses are put on the field with the sizes of $3600 \times 3600 \mathrm{~mm}$ instead of soils. The setting of tomato position is the same with the rail-style area.

The required specifications for robots are shown in Table 1. The projected area of the robot on the ground is within the 800 x $800 \mathrm{~mm}$ square including a box for storing tomatoes, and no height limitation. The robots should have an emergency stop switch on the easy-to-find location of robots. As recommendations, the weight of the robot is less than $50 \mathrm{~kg}$ and the electric power of each motor is less than $70 \mathrm{~W}$.

The robots are classified mainly two types, manual control and autonomous control, and the former robots are classified by whether the operator observes tomato directly or indirectly using cameras mounted on robots, and by robot locomotion whether the robot uses rail or not. Totally, the robots are categorized into 6 types depend on operation and locomotion method as shown in Table 2. The success points for a tomato change depending on robot categories. the point for one tomato of category (1) manual control, direct tomato observation, and rail-type is 2 , and that of category (6) autonomous control, freetype is 16 .

The senior league consists of 3 stages as shown in Fig.2. In first stage, the basic function of the robot is evaluated whether the robot can move, have a manipulator and an end-effector, and recognize tomato. Single tomatoes are hanged from a bar and the robot that can touch a tomato proceeds to the second stage.

In the second stage, the robot harvests a tomato from a tomato cluster. If the robot gives damage to tomato, get -1 point for each damage tomato, and the damage to tomato plant is big minus points. And the target tomatoes should be redder than the reference tomato indicated by the committee. In the final stage, the robots harvest tomato from plant body as shown in Fig. 3, for the 1 st competition.

Table 1 Required Specifications for Robots

\begin{tabular}{|c|c|c|}
\hline \multirow{2}{*}{ Requirement } & Max. Size & $\begin{array}{c}\text { W:800mm D:800mm No height } \\
\text { limitation }\end{array}$ \\
\cline { 2 - 3 } & Safety & Emergency Stop Switch \\
\hline \multirow{2}{*}{ Recommend } & Max. Weight & Max. 50kg \\
\cline { 2 - 3 } & $\begin{array}{c}\text { Max. Motor } \\
\text { Power }\end{array}$ & Max. 70W each \\
\hline
\end{tabular}


Table 2 Robot Classification by Operation Method

\begin{tabular}{|c|c|c|c|c|c|c|}
\hline $\begin{array}{l}\text { Robot } \\
\text { Control }\end{array}$ & \multicolumn{4}{|c|}{ Manual } & \multirow{2}{*}{\multicolumn{2}{|c|}{$\frac{\text { Antonomous }}{\text { at and Stop commands }}$}} \\
\hline $\begin{array}{c}\text { Operator } \\
\text { Manipulation }\end{array}$ & \multicolumn{2}{|c|}{$\begin{array}{c}\begin{array}{c}\text { Direct Observation of } \\
\text { Tomato }\end{array} \\
\end{array}$} & \multicolumn{2}{|c|}{$\begin{array}{c}\text { Intirect Observation of } \\
\text { Tomato }\end{array}$} & & \\
\hline $\begin{array}{c}\text { Modle of } \\
\text { Locomotion }\end{array}$ & Railtype & Freetype & Rail type & Free-type & Railtype & Free-type \\
\hline Catrgary & (1) & (2) & (3) & (4) & (5) & (6) \\
\hline
\end{tabular}

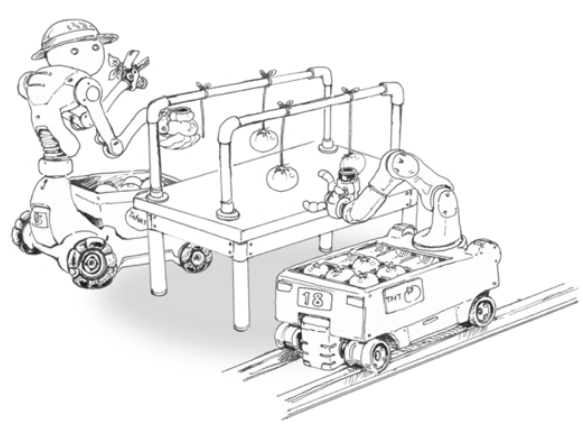

(A) FIRST STAGE: PICK UP SINGLE TOMATO

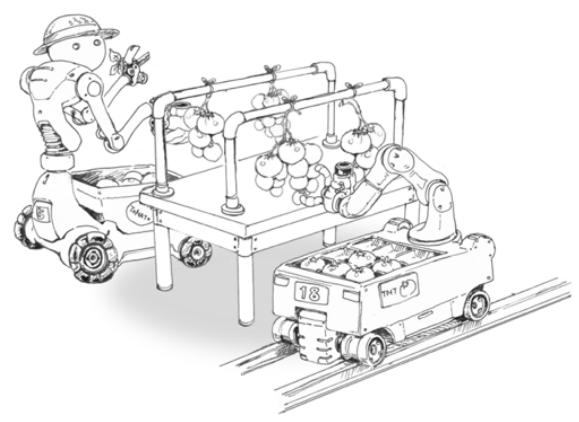

(B) SECOND STAGE: PICK UP A TOMATO FROM TOMATO CLUSTER

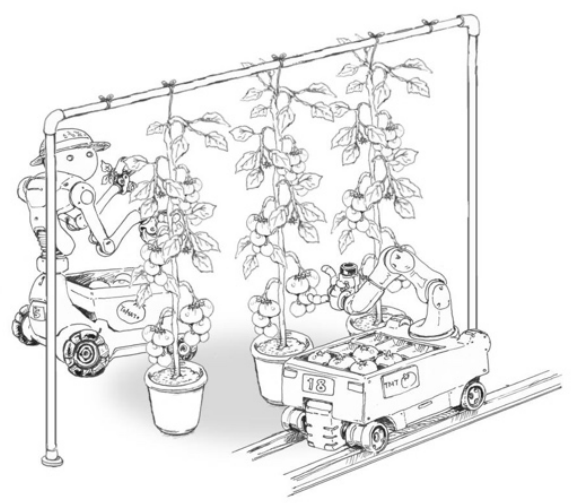

(C) FINAL STAGE: PICK UP A TOMATO FROM TOMATO PLANT

Fig. 1 The three stages of the senior league.

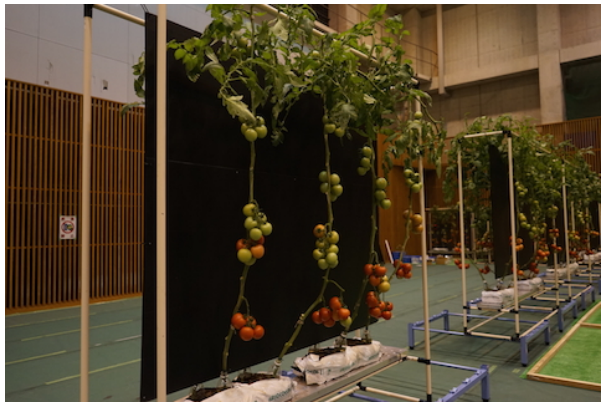

Fig. 2 The overview of the final stages of the senior league in the 1 st competition

\subsection{Ju 2.2 Junior League}

Figure 3 shows the concept of Junior League. We set the subjects to make the model of an autonomous transport system of tomatoes harvesting, such as the transportation and sorting of harvested tomatoes. Competition subjects are shown below.

(1) Line Trace

The robot moves along the white course line using the color sensor. In the harvest field, Tomato boxes are arranged. The robot can find three RGB colored tomato boxes if moves along the line.

\section{(2) Color Identification}

The robot explores the area and recognize color signs along course line, and find three RGB colored tomatoes in boxes (tomato box).

(3) Mechanism Design and Control

To pick up the tomato boxes, participants are expected to design and make a robot arm to get a tomato box. The robot is required to store, transport and relocate the boxes to the assigned storage area. After picking up the box, the robot is to return to the course line. Then, the robot carries the box to the specific storage location.

(4) Object detection

After putting the tomato boxes to the storage locations, the robot should return to the course line. Finally, the robot goes the charging station which is put at the position with a certain distance away from the course line. The robot must find the stop position by the distance measuring sensor.

Each team consists of 3 or 4 students and makes a robot using LEGO Mindstorms. The basic specification for robot is that the sizes of the robot are within $300 \times 300[\mathrm{~mm}]$ on the ground. The robot can have structural change after starting, so that the initial robot structure is regarded as the robot size. 


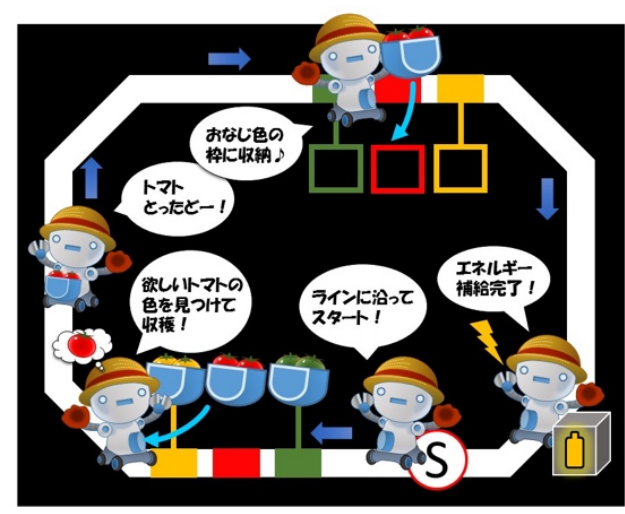

Fig. 3 The concept of Junior League

\section{Regulation Changes toward Smart Agriculture}

The regulation of the competition is changed by evaluating the achievement of teams toward actual greenhouse toward smart agriculture.

Table 3 shows the history of regulation changes. The first competition was held in 2014 with Senior League. From the second competition, Junior League started as the outreach activity of agricultural robotics. From the third competition, a bump was put on the free-style area to motivate the improvement of mobility for rough terrain. In the fifth competition, the black board shown in Fig.2, which is placed for making the image processing easy, was removed and the robot are asked to find tomatoes in various colors. From the 7th competition in 2020, the working field moved to an experimental greenhouse, so that the robot need the color consistency algorithm against sunlight environment. Junior league was held as in each school via internet.

The winner teams are shown in Table 4. The first winner robot from team JSK, the Univ. of Tokyo (Fig.4) joined the category (T-4) and the robot was operated by human in the remote place and succeeded to have 5 tomatoes in $10 \mathrm{~min} .2$ teams joined to autonomous categories could not harvest a tomato. In the 6th competition, the robot of Kyutech team whose category is T-5 autonomous robot for the rail-style field (Fig.5), succeeded to harvest 13 tomatoes in $10 \mathrm{~min}$ in the 2nd stage and 5 tomatoes in the final stage. The teams selected for the final stage of 7 th competition, all teams entries for the category T-5, autonomous robot in the rail-style field. The winner is the team of National Institute Technology, Kitakyushu College (Fig.6) succeeded to take about 20 tomatoes in the greenhouse. The performance of each team grows up to harvest tomatoes autonomously in spite of the lighting condition changes. Moreover, some journal papers are published based on the results of the competitions such as [7][8][14]15].

Table 3 History of regulation changes

\begin{tabular}{|c|c|c|}
\hline $\mathrm{N}-$ th & Year & Rule \& Changes \\
\hline 1 & 2014 & $\begin{array}{l}\text { Senior League started with } 6 \text { categories from T1 (manual operation) to T6 (autonomous) and } 2 \\
\text { kinds of working fields (rail and artificial grass) in indoor field (Gymnastium). The black boards } \\
\text { are set behind tomato plants. }\end{array}$ \\
\hline 2 & 2015 & $\begin{array}{l}\text { Senior: No rule change. } \\
\text { Junior: Junior League started. Lego mindstorm is used for basic platform. }\end{array}$ \\
\hline 3 & 2016 & $\begin{array}{l}\text { Senior: Bump is placed in the center of grass field. } \\
\text { Junior: No rule chage. }\end{array}$ \\
\hline 4 & 2017 & No rule change. \\
\hline 5 & 2018 & $\begin{array}{l}\text { Senior: Slope is placed instead of Bump in the grass field. The black boards are removed. In } \\
\text { scoring, success rate is added. } \\
\text { Junior: Original arm made of stationery is allowed. Tomato box removed. }\end{array}$ \\
\hline 6 & 2019 & No rule change. \\
\hline 7 & 2020 & $\begin{array}{l}\text { Senior: Video evaluation instaed of } 1 \mathrm{st} \text { and } 2 \text { nd rounds. The cometition field is changed to the } \\
\text { ourdoor experimental green house. The grass field is changed to the soil field. } \\
\text { Junior: Online cometition in each school. }\end{array}$ \\
\hline
\end{tabular}

Table 4 Results of competition and Winner teams

\begin{tabular}{|c|c|c|c|c|c|}
\hline $\mathrm{N}$-th & Year & Senior T & or $\mathrm{T}$ & s Winner & 2nd Place \\
\hline 1 & 2014 & 9 & - & $\begin{array}{l}\text { Inaba-Okada Lab., Univ. } \\
\text { of Tokyo }\end{array}$ & $\begin{array}{l}\text { National Institute of } \\
\text { Technology, } \\
\text { Kitakyushu College }\end{array}$ \\
\hline 2 & 2015 & 14 & 16 & Hayashi Lab., Kyutech & Team SS \\
\hline 3 & 2016 & 12 & 23 & Kyushu Polytech & NAIST \\
\hline 4 & 2017 & 12 & 18 & Hayashi Lab., Kyutech & Ishii Lab., Kyutech \\
\hline 5 & 2018 & 9 & 23 & Hayashi Lab., Kyutech & Kyushu Polytech \\
\hline 6 & 2019 & 9 & 25 & Ishii Lab., Kyutech & NAIST \\
\hline 7 & 2020 & 8 & 13 & $\begin{array}{l}\text { National Institute of } \\
\text { Technology, Kitakyushu } \\
\text { College }\end{array}$ & Hayashi Lab., Kyutech \\
\hline
\end{tabular}

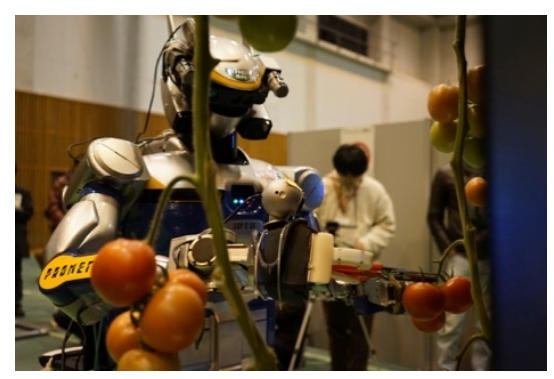

Fig.4 The winner robot of the 1st competition, JSK team from Univ. of Tokyo. 


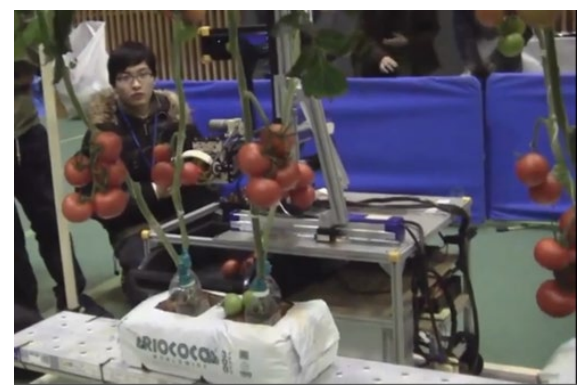

Fig. 5 The winner robot of the 6th competition, Kyutech team. The robot harvested 5 tomatoes in the final stage.

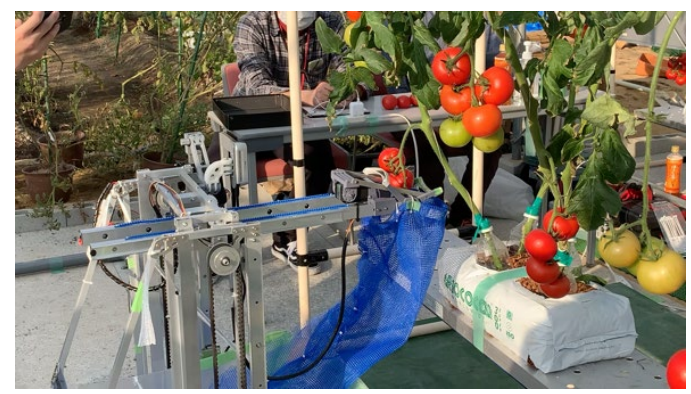

Fig.6 The winner robot of the 7th competition, National Institute of Technology, Kitakyushu College. The robot harvested 20 tomatoes in the experimental greenhouse.

\section{Summary}

We have organized the Tomato-Harvesting-Robot competition to promote agricultural robots and provide the test field for tomato harvesting. The performance of robots are growing up gradually and the regulation of the competition is revised to be closed to the actual working environment. Currently, the winner robot can harvest a tomato within 30 seconds in the sunlight condition. In the next, we expect to have robots working in the soil field and in the night time.

\section{Acknowledgements}

The Tomato-Harvesting-Robot competition is supported by FAIS, Kitakyushucity, Hibikinada Green Farm, and YASKAWA Electric Corporation.

\section{References}

1. N. Noguchi, “Agricultural Vehicle Robot," J. Robot. Mechatron., Vol.30, No.2, pp. 165-172, 2018.

2. Kawamura et. al., Study on agricultural robot (1st report), The journal of JASM , vol. 46 No.3,pp.353-358, 1984 (in Japanese).

3. Kawamura et. al., Study on agricultural robot (2nd report), The journal of JASM, vol.47 No. 2, pp.177-182, 1985 (in Japanese).
4. Kondo, et.al., A Machine Vision System for Tomato Cluster Harvesting Robot, Engineering in Agriculture, Environment and Food, Vol. 2, No. 2, pp.60-64, 2009.

5. Kondo, et.al, Development of an End-Effector for a Tomato Cluster Harvesting Robot, Engineering in Agriculture, Environment and Food, Vol. 3, No. 1, pp.20-24, 2010.

6. Ota et. al., Development of a Tomato Harvesting Robot with a Vision System Using Specular Reflection (Part 1), the journal of JASM, vol. 72 No.6, pp.595-603, 2010.

7. H. Yaguchi, K. Nagahama, T. Hasegawa, and M. Inaba, "Development of An Autonomous Tomato Harvesting Robot with Rotational Plucking Gripper, 2016 IEEE/RSJ Int. Conf. on Intelligent Robots and Systems, pp. 652-657, 2016.

8. H. Yaguchi, T. Hasegawa, K. Nagahama, M. Inaba, A Research of Construction Method for Autonomous Tomato Harvesting Robot focusing on Harvesting Device and Visual Recognition, J. Robot. Soc. Jpn., Vol. 36, No.10, pp. 693-702, (in Japanese with English summary), 2018.

9. T. Yoshida, T. Fukao, and T. Hasegawa, Fast Detection of Tomato Peduncle Using Point Cloud with a Harvesting Robot, J. Robot. Mechatron., Vol.30, No.2, pp. 180-186, 2018.

10. T. Yoshida, T. Fukao, and T. Hasegawa, Cutting Point Detection Using a Robot with Point Clouds for Tomato Harvesting, J. Robot. Mechatron., Vol.32, No.2, pp. 437-445, 2020.

11. T. Fukatsu and M. Hirafuji, Field Monitoring Using SensorNodes with a Web Server, J. Robot. Mechatron., Vol.17, No.2, pp. 164- 172, 2005.

12. R. Fukui, K. Kawae, and S. Warisawa, Development of a Tomato Volume Estimating Robot that Autonomously Searches an Appropriate Measurement Position - Basic Feasibility Study Using a Tomato Bed Mock-Up -, J. Robot. Mechatron., Vol.30, No.2, pp. 173-179, 2018.

13. L. Itti et al., A model of saliency-based visual attention for rapid scene analysis, IEEE Trans. on Pattern Analysis and Machine Intelligence, Vol.20, No.11, pp. 1254-1259, 1998.

14. Takuya Fujinaga et al., Image Mosaicing Using Multi-Modal Images for Generation of Tomato Growth State Map, J. Robot. Mechatron., Vol.30, No.2, pp. 187-197, 2018.

15. Takuya Fujinaga, et al., Tomato Growth State Map for the Automation of Monitoring and Harvesting, J. Robot. Mechatron., Vol.32, No.6, pp. 1279-1291, 2020. 